\title{
Recovery of Spermatogenesis Following Cancer Treatment with Cytotoxic Chemotherapy and Radiotherapy
}

\author{
Keisuke Okada®i, Masato Fujisawa \\ Division of Urology, Department of Surgery Related, Kobe University Graduate School of Medicine, Kobe, Japan
}

\begin{abstract}
The survival rates of boys and men with cancer have increased due to advances in cancer treatments; however, maintenance of quality of life, including fertility preservation, remains a major issue. Fertile male patients who receive radiation and/or chemotherapy face temporary, long-term, or permanent gonadal damage, particularly with exposure to alkylating agents and whole-body irradiation, which sometimes induce critical germ cell damage. These cytotoxic treatments have a significant impact on a patient's ability to have their own biological offspring, which is of particular concern to cancer patients of reproductive age. Therefore, various strategies are needed in order to preserve male fertility. Sperm cryopreservation is an effective method for preserving spermatozoa. Advances have also been achieved in pre-pubertal germ cell storage and research to generate differentiated male germ cells from various types of stem cells, including embryonic stem cells, induced pluripotent stem cells, and spermatogonial stem cells. These approaches offer hope to many patients in whom germ cell loss is associated with sterility, but are still experimental and preliminary. This review examines the current understanding of the effects of chemotherapy and radiation on male fertility.
\end{abstract}

Keywords: Drug therapy; Infertility, male; Radiation; Spermatogenesis

This is an Open Access article distributed under the terms of the Creative Commons Attribution Non-Commercial License (http://creativecommons.org/licenses/by-nc/4.0) which permits unrestricted non-commercial use, distribution, and reproduction in any medium, provided the original work is properly cited.

\section{INTRODUCTION}

Cancer treatment focuses on curing the disease itself, whereas individuals place an emphasis on treatment safety and efficacy. The American Cancer Society estimated that 10,380 new cancer cases and 1,250 deaths from cancer occurred in 2016 among males and females aged 0 to 14 years [1]. Infertility is an important longterm adverse effect in males despite recent advances in treatments for malignancies that may cure young can- cer patients [2-6]. Increasingly many young adults are long-term survivors of cancer. Patients younger than 15 years of age undergoing cancer treatment are projected to have a 5 -year cancer survival rate of $75 \%$ [7]. More than $50 \%$ of these young male survivors will desire paternity after treatment, including $75 \%$ of those who were childless at the time of diagnosis [8].

Although chemotherapy and radiation therapy for malignancies are highly effective, their associated gonadotoxic side effects may severely impair fertility in

Received: May 28, 2018 Revised: Jun 10, 2018 Accepted: Jun 10, 2018 Published online Nov 27, 2018

Correspondence to: Keisuke Okada iD https://orcid.org/0000-0002-2819-6047

Division of Urology, Department of Surgery Related, Kobe University Graduate School of Medicine, 7-5-1 Kusunoki-cho, Chuo-ku, Kobe, 6500017, Japan.

Tel: +81-78-382-6155, Fax: +81-78-382-6169, E-mail: keisuke.okada@outlook.com 
agent- and dose-dependent manners and may cause temporary or permanent gonadal toxicity in male patients [9]. The resumption of spermatogenesis after various types of therapies is unpredictable, and studies on spermatogenesis in long-term cancer survivors have provided evidence of persistent azoospermia or severe oligozoospermia in up to $24 \%$ of cases [10]. Nonetheless, the eventual return of sperm production in many posttreatment cancer patients has prompted the question of whether post-therapy spermatozoa are a suitable option for conception, either naturally or via assisted reproductive technologies.

Spermatogenesis may still continue over several years if the spermatogonial cell population is not completely depleted. If a population of these germ stem cells remains after cancer treatment, the regeneration of spermatozoa may continue for years [11].

Sperm cryopreservation is a well-established technique and is offered before cancer treatment in case of azoospermia in the future. New fertility preservation options, such as the generation of gametes from embryonic stem (ES) or induced pluripotent stem (iPS) cells, have been developed that may change reproductive options for men and boys facing germ-cell loss and sterility. It is very important to inform patients and family facing infertility of this possible side effect of their treatment, as well as all the options available to prevent it, because the recovery of gonadal function after cancer treatment remains unpredictable.

One of the aims of this review is to discuss the pathophysiology of male infertility caused by radiation and/or chemotherapy for cancer treatment. The other aim is to review the use of sperm cryopreservation to maintain fertility and to discuss new fertility preservation strategies.

\section{RADIATION}

Radiation therapy remains the main treatment option for many malignant cancers in men of reproductive age. The testis is one of the most radiosensitive organs. Animal data indicate that the fractionation of radiotherapy increases its gonadal toxicity, and evidence suggests that this also occurs in humans. Gonadal damage caused by radiotherapy depends on the gonadal dosage and how radiation is delivered. Damage may be caused during direct irradiation of the testis or, more commonly, from scattered radiation during treat- ment directed at adjacent tissues.

Testes directly exposed to ionizing radiation exhibit germ cell loss and Leydig cell dysfunction [12,13]. The testes do not need to be directly irradiated in order for spermatogenic impairment to occur; if the radiation field is proximal to a testis and the dose is sufficient, sperm production may be diminished even if the testes are shielded [14]. Radiation therapies begin to affect spermatogenesis gradually from 0.1 to $1.2 \mathrm{~Gy}$ and induce irreversible gonadal damage at $4 \mathrm{~Gy}$ [15]. The function of the testes may be significantly impaired by very low doses of radiation therapy. The effects of lowdose and single-fraction irradiation on spermatogenesis in healthy men have been discussed [16]. Doses as low as 0.1 Gy may cause morphological and quantitative changes to spermatogonia, which are radiosensitive immature cells. At doses of 2 to 3 Gy, spermatocytes are damaged and spermatid numbers decrease. Doses of 4 to 6 Gy result in significant reductions in the numbers of spermatozoa and damage to spermatids.

The dose limits at which azoospermia becomes permanent remain unclear. Doses of more than 1.2 Gy are known to increase the recovery time of spermatogenesis [16]. Reductions in sperm count following damage to the testes by radiation doses of up to 3 Gy have been noted after 60 to 70 days. Radiation doses of 4 Gy reduce sperm concentrations because of damage to spermatids. Radiation doses of less than 0.8 Gy may result in oligospermia, whereas those greater than 0.8 Gy may lead to azoospermia [17]. Another study showed that a radiation dose of 7.5 Gy or higher to the testes for childhood cancer decreased the chance of these patients having their own children [18].

According to a study on boys with acute lymphoblastic leukemia who received radiotherapy for the testis at doses of 12, 15, and $24 \mathrm{~Gy}$, all became azoospermic, while doses less than 24 Gy had no effect on testosterone levels [19]. Elevated gonadotropin levels were observed and subclinical Leydig cell damage was suspected. Leydig cells are considered to be more resistant to radiation-induced damage at a dose of up to $30 \mathrm{~Gy}$ [20]. According to a survey, the recovery of spermatogenesis may start at least 9 years after treatment [21]. However, better techniques that enable more accurate dose delivery and protection of the gonads have resulted in earlier complete recovery of spermatogenesis, at 9 to 18 months after radiation at doses up to $1 \mathrm{~Gy}, 30$ months at doses up to 2 to $3 \mathrm{~Gy}$, and 5 years at doses up to 4 
Gy.

According to a study presenting findings from longterm follow-up of stage I and IIA seminoma patients after radiation therapy, $64 \%$ achieved natural pregnancy and $50 \%$ showed complete recovery of spermatogenesis [22].

Although radiation typically acts by killing cells immediately by apoptosis or when they attempt to proliferate or divide, the minimum number of type $\mathrm{A}$ spermatogonia after single radiation dose between 0.2 and 4 Gy was not reached rapidly, but as the result of a progressive decline over the course of approximately 21 weeks [23-25]. The reasons for this gradual decline currently remain unknown, but may be due in part to some of the non-cycling A stem spermatogonial population only expressing lethal damage when they are recruited into the cycle. Furthermore, the differentiation of spermatogonia into spermatocytes is reduced during this time [26]. This phenomenon has been observed in rats and indicates somatic damage, or at least altered signaling from somatic cells.

The ability to differentiate into spermatocytes and later stages increases approximately 21 weeks after radiation therapy. The number of type A spermatogonia begins to increase at this time, suggesting that selfrenewal exceeds cell loss. The timing of the recovery depends on the dose of radiation. It begins 7 months after irradiation with a single dose of $1 \mathrm{~Gy}$ and takes 24 months after irradiation with 6 Gy. Complete recovery of the sperm count to the pre-irradiation level requires approximately 2 years after a single dose of $1 \mathrm{~Gy}$.

High doses of radiation therapy may kill all spermatogonial stem cells (SSCs), resulting in permanent azoospermia. Previous studies reported that only approximately $15 \%$ of patients recovered their sperm count or fertility after single doses of approximately 10 Gy $[27,28]$. It is important to note that responses to the doses administered above were for single doses of radiation, which have been examined in the greatest detail. Fractionated radiation used for cancer treatments for 3 to 4 weeks causes greater delays in spermatogenic recovery and leads to permanent azoospermia. Sandeman [29] showed that a total gonadal dose of more than 2.5 Gy of fractionated radiation generally resulted in permanent azoospermia.

In a previous study, all patients who received a testicular dose of radiation of 1.2 to $3.0 \mathrm{~Gy}$ in 14 to 26 fractions for Hodgkin disease became azoospermic after the treatment [30]. An update of this study revealed that spermatogenesis did not recover in patients receiving doses of 1.4 to 2.6 Gy over a follow-up period ranging between 17 and 43 months. However, fertility returned in 2 patients with testicular radiation doses of $1.2 \mathrm{~Gy}$, suggesting a threshold for permanent testicular damage [31]. Another study reported the effects of radiation on follicle-stimulating hormone (FSH) levels and the sperm count during the treatment of Hodgkin disease [32]. Testicular doses of less than 0.2 Gy had no significant effects on FSH levels or sperm count, whereas doses between 0.2 and 0.7 Gy increased FSH levels and reduced the sperm concentration. Lower doses of radiation to the testes were associated with better recovery rates for spermatogenesis. The recovery length of spermatogenesis after modest radiation therapy that may kill some stem cells is longer than that after a chemotherapy regimen that may not kill stem cells.

The mechanisms by which prostate radiotherapy affects reproductive function have recently been reported. If the dose received by the testes from $\mathrm{I}^{125}$ brachytherapy of the prostate is close to $0.18 \mathrm{~Gy}$, prostate brachytherapy has almost no effect on spermatogenesis. However, due to the prolonged half-life of the isotopes used, attempts at conception were delayed for up to 3 to 12 months after treatment [33,34].

\section{CHEMOTHERAPY}

In addition to radiation, most chemotherapeutic drugs are considered to be toxic to the gonads, particularly alkylating medications. Many studies have investigated cyclophosphamide, which is used in the treatment of immunological diseases or in combination chemotherapy for hematological and testicular cancers. Most studies have focused on semen analyses and biochemical markers of fertility. Although the end point of the assessment of male factor fertility is the achievement of fatherhood, survivors of cancer may be less likely to find a partner or may not want their own children. This may be because of the psychological effects of the disease or treatment and because of the genetic risk in the offspring of patients subjected to cytotoxic treatments. Female factors that may influence the couple's fertility are also difficult to identify.

Many combination chemotherapies used in the treatment of cancer also produce reductions with a similar 
time course. Due to toxicity to later stage germ cells, 10 to 100 -fold decreases in sperm counts may occur within 1 to 2 months, while azoospermia generally does not occur until after 2 months, when sperm are derived from differentiating spermatogonia [35,36]. Although sperm are produced for several months after the start of cytotoxic therapies, pregnancy needs to be avoided during this period because of a higher risk of genetic damage to sperm.

Similar to radiation therapy, Leydig cells may incur damage following chemotherapy, resulting in subsequent hypogonadism [37]. Although side effects have been minimized with advances in the delivery of chemotherapy using synergistic agents at lower toxic doses, a risk of infertility remains. The extent of gonadal damage is largely dependent on the drug type, age of the patient, and amount of the chemotherapeutic agent administered. Table 1 summarizes some chemotherapy drugs and their effects on spermatogenesis.

Alkylating agents, particularly mustards, are among the most potent germ cell mutagens, inducing dominant lethality, heritable (reciprocal) translocations, and specific locus mutations in post-stem cell stages [38,39]. Three alkylating anticancer drugs (melphalan, mitomycin $\mathrm{C}$, and procarbazine) have been shown to induce specific locus mutations in SSCs; however, no chemical has yet been shown to induce transmissible chromosomal translocations (dominant lethality and heritable translocations) in stem cells [40]. Chemotherapy with alkylating agents, with or without radiation to sites below the diaphragm, has been associated with a fertility deficit in approximately $60 \%$ of men [41]. The duration and permanence of induced azoospermia depends on the dose of the cytotoxic agent and the additive effects of different agents. When cyclophosphamide is given as a single agent, doses of $19 \mathrm{~g} / \mathrm{m}^{2}$ are required for prolonged azoospermia [35]. A follow-up of 26 male patients with azoospermia after the cessation of cyclophosphamide showed the return of spermatogenesis in 12 patients within 15 to 49 months (mean, 31 months) [42]. According to another study of 116 males treated with cyclophosphamide alone, 52 showed evidence of testicular dysfunction after the treatment [17]. The incidence of gonadal dysfunction was related to the total dose of cyclophosphamide. More than $80 \%$ of postpubertal patients received more than $300 \mathrm{mg} / \mathrm{kg}$ of cyclophosphamide. Since busulfan is very effective as a single agent for killing SSCs in rodents and monkeys, it is the alkylating agent with the strongest sterilizing effect [43].

Limited information is currently available on parenthood rates after treatment for Hodgkin disease. According to one study, only 18 out of 101 men who had received chemotherapy, radiotherapy, or both for Hodgkin disease over a 21-year period had fathered a child. Twelve of those men had been treated with radiotherapy only [44]. Another study showed improved fatherhood rates following chemotherapy or radiotherapy for Hodgkin disease. Twenty-five of 51 men (49\%) were able to have their own children [45]. The chemotherapy regimens used for the treatment of nonHodgkin lymphoma (NHL) are generally considered to be less gonadotoxic than those for Hodgkin disease. According to one study, all 71 patients treated with CHOP (cyclophosphamide, doxorubicin, vincristine, and prednisolone)-based chemotherapy were rendered azoospermic during the treatment, while $67 \%$ recovered to normospermic levels 5 years after the treatment, with

Table 1. Summary of fertility in adult men following treatment with various gonadotoxic drugs

\begin{tabular}{|c|c|c|c|}
\hline Group & Definite gonadotoxicity & Diagnosis & Effect on spermatogenesis \\
\hline Alkylating agents & $\begin{array}{l}\text { Cyclophosphamide, busulfan, } \\
\text { chlorambucil, procarbazine, etc. }\end{array}$ & HL, NHL, GCT, sarcomas & $\begin{array}{l}\text { May induce azoospermia within } \\
90 \text { days }\end{array}$ \\
\hline Platinum-based agents & Cisplatin, carboplatin & HL, NHL, GCT, bladder cancer & $\begin{array}{l}\text { Spermatogenesis affected, possible } \\
\text { chromosomal aberrations }\end{array}$ \\
\hline Vinca alkaloids & Vincristine, vinblastine & $\mathrm{HL}, \mathrm{NHL}$, leukemia & $\begin{array}{l}\text { Spermatogenesis arrested, } \\
\text { spermatozoa motility reduced }\end{array}$ \\
\hline Antimetabolites & Cytarabine & $\begin{array}{l}\mathrm{HL}, \mathrm{NHL} \text {, leukemia, bladder } \\
\text { cancer, colorectal cancer }\end{array}$ & $\begin{array}{l}\text { Spermatogenesis affected, possible } \\
\text { chromosomal aberrations }\end{array}$ \\
\hline Topoisomerase inhibitors & Etoposide, doxorubicin & $\mathrm{HL}, \mathrm{NHL}, \mathrm{GCT}$, sarcomas & $\begin{array}{l}\text { Cytotoxic with possible } \\
\text { chromosomal anomalies }\end{array}$ \\
\hline
\end{tabular}

HL: Hodgkin lymphoma, NHL: non-Hodgkin lymphoma, GCT: germ cell tumor.

Adapted from Howell and Shalet (J Natl Cancer Inst Monogr 2005;(34):12-7) [16], and Osterberg et al (Urol Ann 2014;6:13-7) [38]. 
a further 5\% being oligospermic [46]. The lower incidence of permanent infertility in men treated for NHL than in Hodgkin disease patients may be related to the absence of procarbazine in the standard regimens used for NHL [47]. Furthermore, the use of lower doses of alkylating agents may also be important. The absence of procarbazine and alkylating drugs is also a likely explanation for the reduced toxicity of ABVD (doxorubicin hydrochloride [Adriamycin], bleomycin, vinblastine, and dacarbazine) [48].

Cisplatin and cyclophosphamide were investigated as the test chemical and positive control, respectively, to assess their cytogenetic effects on spermatogonia in mice 24 hours after a treatment with single exposure. The different doses of the chemicals tested in mice were cisplatin at 2,3 , and $5 \mathrm{mg} / \mathrm{kg}$ and cyclophosphamide at $40 \mathrm{mg} / \mathrm{kg}$. This study showed that each dose of cisplatin induced a significant number of chromosomal aberrations, mostly chromatid breaks and fragments [49]. According to an analysis of 170 patients who received cisplatin-based chemotherapy for testicular germ cell cancer for at least 1 year, the post-chemotherapy count was normospermic in $64 \%$, oligospermic in $16 \%$, and azoospermic in $20 \%$ of 89 patients whose prechemotherapy counts were normospermic. There was clear evidence for continued recovery after 1 year, as the probability of spermatogenesis increased to $48 \%$ by 2 years and $80 \%$ by 5 years. The probability of recovery to oligospermic and normospermic count levels was significantly higher in 54 patients treated with carboplatin-based therapy than in those treated with cisplatinbased therapy [50].

According to rat data, vinblastine did not cause any significant changes in the incorporation of $\left[{ }^{3} \mathrm{H}\right]$ thymidine at any stage in the seminiferous epithelial cycle; however, some time-dependent reductions were observed, particularly at stages I and VIII [51]. Another study on mice showed that spermatogonia were resistant to the actions of vinblastine with no observable loss, even at a dose of $7 \mathrm{mg} / \mathrm{kg}$ [52]. However, vinblastine exhibited the ability to induce the arrest of mitotic metaphase in rat spermatogonia [53] and inhibited meiotic division in mouse and rat spermatocytes [54,55].

The induction of structural chromosomal aberrations by bleomycin was studied in the bone marrow cells and spermatogonia of mice at doses of 10,20,40, and $80 \mathrm{mg} /$ $\mathrm{kg}$. Bleomycin induced genetically important reciprocal translocations in stem-cell spermatogonia, as measured with the spermatocyte test, and the response of bone marrow cells to bleomycin was not markedly different from that of spermatogonia [56].

\section{TREATMENT FOR IMPAIRED SPERMATOGENESIS}

Even if a patient's semen analysis shows azoospermia after radiotherapy and/or chemotherapy for malignant cancer, some sperm may still be present in the testis. Spermatozoa were retrieved from the testes by microdissection testicular sperm extraction in 37\% of patients who were azoospermic after chemotherapy [57]. According to a previous study, sperm do not survive epididymal transit and do not reach the ejaculate if the human testis contains fewer than 3-4 million sperm [58]. The success rate of retrieving sperm by testicular sperm extraction is related to the presence of residual hypospermatogenesis in the testis. The success rate was higher in patients treated with alkylating agents than in those treated with agents that are toxic to stem cells and/or the somatic environment.

In adolescent males who have already entered puberty, the most established approach to preserving fertility is the cryopreservation of ejaculated sperm. Cryopreserved sperm may be used later in life for intrauterine insemination or in vitro fertilization, with or without an intracytoplasmic sperm injection. In most males, the process of providing sperm for cryopreservation is effective, inexpensive, and non-invasive because most adolescent males are able to provide ejaculated semen. However, options are limited to experimental techniques for prepubertal males. Prepubertal testicular tissue banking under an Institutional Review Board-approved protocol is currently available at several institutions [9].

The option of the preservation of one's own semen before gonadotoxic treatment is not available for prepubertal boys, and in such patients, only the necessary amount of testicular tissue has to be removed for cryopreservation for future offspring. A morphological study estimated that 1 testis of a 10-year-old pre-pubertal boy contains approximately $83 \times 10^{6}$ germ cells [59].

Regarding male infertility following chemotherapy and/or radiation, stem cell therapy to generate male gametes may represent a promising treatment strategy. Stem cells are defined as having the potential for self-renewal and differentiation. Three major stem cell 
sources were recently identified for the generation of male differentiated germ cells: ES cells, iPS cells, and SSCs. ES cells are derived from the inner cell mass of developing blastocysts. The first human ES cell line was established in 1998 [60]. Advances have since been made in the derivation of differentiated male germ cells from mouse or human ES cells [61-63]. Transcription factors were used to reprogram somatic cells to iPS cells in 2006 [64]. A recent study demonstrated that iPS cells generate haploid spermatids [65]. SSCs have the ability to self-renew and differentiate into male gametes (i.e., mature spermatozoa) in the testis throughout life [66] Recent studies showed that spermatogonia, including SSCs, may be induced to differentiate into differentiated male germ cells, eventually resulting in haploid spermatids.

Although sperm DNA damage occurs following chemotherapy or radiotherapy, an increase in genetic defects or congenital malformations was not detected among children conceived by parents who had previously undergone treatments. However, the use of assisted reproductive technologies and micromanipulation techniques may increase this risk [67].

\section{CONCLUSIONS}

Cancer and its cytotoxic treatments may impair male fertility in various manners, thereby excluding these men from the opportunity to father offspring. Improvements in the toxicity of cancer treatment and the selective delivery of therapeutic agents will result in better outcomes, reduced sperm damage, and earlier recovery of spermatogenesis. All men wishing to have their own children after gonadotoxic treatment need to be counselled properly by a fertility specialist regarding the potential risks of their disease and the side effects of therapy, as well as the possibility of fertility recovery.

Male factor infertility is a known side effect of cancer treatment. All patients need to be thoroughly educated about the impact of cancer treatment on their fertility and provided with numerous options to preserve their future fertility potential. It is currently very difficult to predict which patients will recover spermatogenesis and which will remain azoospermic. No parameters help predict which patients will remain permanently sterile.

Therefore, semen analyses to test sperm count and quality before radiotherapy and/or chemotherapy need to be offered to male patients for future family planning. The cryopreservation of sperm before treatment also needs to be suggested. Sperm cryopreservation is the only clinical method currently available. Fertility maintenance is still an issue in younger boys, and extensive efforts are being made to improve techniques for testicular tissue or spermatogonial cryopreservation and transplantation and testis xenografting. However, they are not routinely applied due to clinical and ethical reasons.

The cryopreservation of semen is a safe and effective way of preserving fertility for adolescent and adult males. For adult men with azoospermia, testicular sperm extraction is necessary and is the only option for retrieving sperm. However, fertility preservation options for pre-pubertal males are limited; therefore, patients and their families need to be counseled before treatments by a specialist in fertility preservation. The creation of spermatozoa from ES cells, iPS cells, and SSCs is theoretically an option for eventual reproduction in men who have lost their testicular germ cells. Although still a topic of research, further developments of this technology are expected in the near future.

\section{Disclosure}

The authors have no potential conflicts of interest to disclose.

\section{Author Contribution}

Writing (review \& editing): Okada K. Supervision: Fujisawa M.

\section{REFERENCES}

1. Siegel RL, Miller KD, Jemal A. Cancer statistics, 2016. CA Cancer J Clin 2016;66:7-30.

2. Hodgson DC, Pintilie M, Gitterman L, Dewitt B, Buckley CA, Ahmed S, et al. Fertility among female hodgkin lymphoma survivors attempting pregnancy following ABVD chemotherapy. Hematol Oncol 2007;25:11-5.

3. Pectasides D, Pectasides E, Papaxoinis G, Skondra M, Gerostathou M, Karageorgopoulou S, et al. Testicular function in poor-risk nonseminomatous germ cell tumors treated with methotrexate, paclitaxel, ifosfamide, and cisplatin combination chemotherapy. J Androl 2009;30:280-6.

4. Koumarianou AA, Xiros N, Papageorgiou E, Pectasides D, Economopoulos T. Survival improvement of young patients, 
aged 16-2, with Hodgkin lymphoma (HL) during the last three decades. Anticancer Res 2007;27:1191-7.

5. Ishikawa T, Kamidono S, Fujisawa M. Fertility after high-dose chemotherapy for testicular cancer. Urology 2004;63:137-40.

6. Chiba K, Fujisawa M. Fertility preservation in men with cancer. Reprod Med Biol 2014;13:177-84.

7. Landis SH, Murray T, Bolden S, Wingo PA. Cancer statistics, 1999. CA Cancer J Clin 1999;49:8-31.

8. Schover LR, Brey K, Lichtin A, Lipshultz LI, Jeha S. Knowledge and experience regarding cancer, infertility, and sperm banking in younger male survivors. J Clin Oncol 2002;20: 1880-9.

9. Trost LW, Brannigan RE. Oncofertility and the male cancer patient. Curr Treat Options Oncol 2012;13:146-60.

10. López Andreu JA, Fernández PJ, Ferrís i Tortajada J, Navarro I, Rodríguez-Ineba A, Antonio P, et al. Persistent altered spermatogenesis in long-term childhood cancer survivors. Pediatr Hematol Oncol 2000;17:21-30.

11. Pacey AA. Fertility issues in survivors from adolescent cancers. Cancer Treat Rev 2007;33:646-55.

12. Clermont Y. Kinetics of spermatogenesis in mammals: seminiferous epithelium cycle and spermatogonial renewal. Physiol Rev 1972;52:198-236.

13. Bahadur G, Ralph D. Gonadal tissue cryopreservation in boys with paediatric cancers. Hum Reprod 1999;14:11-7.

14. Gandini L, Sgrò P, Lombardo F, Paoli D, Culasso F, Toselli L, et al. Effect of chemo- or radiotherapy on sperm parameters of testicular cancer patients. Hum Reprod 2006;21:2882-9.

15. Ståhl O, Eberhard J, Jepson K, Spano M, Cwikiel M, CavallinStåhl E, et al. Sperm DNA integrity in testicular cancer patients. Hum Reprod 2006;21:3199-205.

16. Howell SJ, Shalet SM. Spermatogenesis after cancer treatment: damage and recovery. J Natl Cancer Inst Monogr 2005;(34): 12-7.

17. Rivkees SA, Crawford JD. The relationship of gonadal activity and chemotherapy-induced gonadal damage. JAMA 1988; 259:2123-5

18. Green DM, Kawashima T, Stovall M, Leisenring W, Sklar CA, Mertens AC, et al. Fertility of male survivors of childhood cancer: a report from the Childhood Cancer Survivor Study. J Clin Oncol 2010;28:332-9.

19. Castillo LA, Craft AW, Kernahan J, Evans RG, Aynsley-Green A. Gonadal function after $12-$ Gy testicular irradiation in childhood acute lymphoblastic leukaemia. Med Pediatr Oncol 1990;18:185-9.

20. Shalet SM, Tsatsoulis A, Whitehead E, Read G. Vulnerability of the human Leydig cell to radiation damage is dependent upon age. J Endocrinol 1989;120:161-5.
21. Hansen PV, Trykker H, Svennekjaer IL, Hvolby J. Long-term recovery of spermatogenesis after radiotherapy in patients with testicular cancer. Radiother Oncol 1990;18:117-25.

22. Nalesnik JG, Sabanegh ES Jr, Eng TY, Buchholz TA. Fertility in men after treatment for stage 1 and $2 \mathrm{~A}$ seminoma. Am J Clin Oncol 2004;27:584-8.

23. Rowley MJ, Leach DR, Warner GA, Heller CG. Effect of graded doses of ionizing radiation on the human testis. Radiat Res 1974;59:665-78.

24. Clifton DK, Bremner WJ. The effect of testicular $\mathrm{x}$-irradiation on spermatogenesis in man. A comparison with the mouse. J Androl 1983;4:387-92.

25. Paulsen CA. The study of radiation effects on the human testis: including histologic, chromosomal and hormonal aspects. Final progress report of AEC contract AT(45-1)-2225, Task Agreement 6. RLO-2225-2. Washington D.C.: US Department of Energy; 1973;1-36.

26. Meistrich ML, van Beek MEAB. Radiation sensitivity of the human testis. Adv Radiat Biol 1990;14:227-68.

27. Sanders JE, Hawley J, Levy W, Gooley T, Buckner CD, Deeg $\mathrm{HJ}$, et al. Pregnancies following high-dose cyclophosphamide with or without high-dose busulfan or total-body irradiation and bone marrow transplantation. Blood 1996;87:3045-52.

28. Jacob A, Barker H, Goodman A, Holmes J. Recovery of spermatogenesis following bone marrow transplantation. Bone Marrow Transplant 1998;22:277-9.

29. Sandeman TF. The effects of $X$ irradiation on male human fertility. Br J Radiol 1966;39:901-7.

30. Speiser B, Rubin P, Casarett G. Aspermia following lower truncal irradiation in Hodgkin's disease. Cancer 1973;32:692 8.

31. Centola GM, Keller JW, Henzler M, Rubin P. Effect of lowdose testicular irradiation on sperm count and fertility in patients with testicular seminoma. J Androl 1994;15:608-13.

32. Kinsella TJ, Trivette G, Rowland J, Sorace R, Miller R, Fraass $\mathrm{B}$, et al. Long-term follow-up of testicular function following radiation therapy for early-stage Hodgkin's disease. J Clin Oncol 1989;7:718-24.

33. Mydlo JH, Lebed B. Does brachytherapy of the prostate affect sperm quality and/or fertility in younger men? Scand J Urol Nephrol 2004;38:221-4.

34. Khaksar SJ, Laing RW, Langley SE. Fertility after prostate brachytherapy. BJU Int 2005;96:915.

35. Meistrich ML, Wilson G, Brown BW, da Cunha MF, Lipshultz LI. Impact of cyclophosphamide on long-term reduction in sperm count in men treated with combination chemotherapy for Ewing and soft tissue sarcomas. Cancer 1992;70:2703-12.

36. Meistrich ML, Wilson G, Mathur K, Fuller LM, Rodriguez 
MA, McLaughlin P, et al. Rapid recovery of spermatogenesis after mitoxantrone, vincristine, vinblastine, and prednisone chemotherapy for Hodgkin's disease. J Clin Oncol 1997;15: 3488-95.

37. Howell SJ, Radford JA, Ryder WD, Shalet SM. Testicular function after cytotoxic chemotherapy: evidence of Leydig cell insufficiency. J Clin Oncol 1999;17:1493-8.

38. Osterberg EC, Ramasamy R, Masson P, Brannigan RE. Current practices in fertility preservation in male cancer patients. Urol Ann 2014;6:13-7.

39. Witt KL, Bishop JB. Mutagenicity of anticancer drugs in mammalian germ cells. Mutat Res 1996;355:209-34.

40. Generoso WM, Witt KL, Cain KT, Hughes L, Cacheiro NL, Lockhart AM, et al. Dominant lethal and heritable translocation tests with chlorambucil and melphalan in male mice. Mutat Res 1995;345:167-80.

41. Byrne J, Mulvihill JJ, Myers MH, Connelly RR, Naughton MD, Krauss MR, et al. Effects of treatment on fertility in longterm survivors of childhood or adolescent cancer. N Engl J Med 1987;317:1315-21.

42. Buchanan JD, Fairley KF, Barrie JU. Return of spermatogenesis after stopping cyclophosphamide therapy. Lancet 1975;2: 156-7.

43. Hermann BP, Sukhwani M, Lin CC, Sheng Y, Tomko J, Rodriguez $\mathrm{M}$, et al. Characterization, cryopreservation, and ablation of spermatogonial stem cells in adult rhesus macaques. Stem Cells 2007;25:2330-8.

44. Swerdlow AJ, Jacobs PA, Marks A, Maher EJ, Young T, Barber JC, et al. Fertility, reproductive outcomes, and health of offspring, of patients treated for Hodgkin's disease: an investigation including chromosome examinations. Br J Cancer 1996; 74:291-6.

45. Aisner J, Wiernik PH, Pearl P. Pregnancy outcome in patients treated for Hodgkin's disease. J Clin Oncol 1993;11:507-12.

46. Pryzant RM, Meistrich ML, Wilson G, Brown B, McLaughlin P. Long-term reduction in sperm count after chemotherapy with and without radiation therapy for non-Hodgkin's lymphomas. J Clin Oncol 1993;11:239-47.

47. Bokemeyer C, Schmoll HJ, van Rhee J, Kuczyk M, Schuppert F, Poliwoda H. Long-term gonadal toxicity after therapy for Hodgkin's and non-Hodgkin's lymphoma. Ann Hematol 1994; 68:105-10.

48. Viviani S, Santoro A, Ragni G, Bonfante V, Bestetti O, Bonadonna $G$. Gonadal toxicity after combination chemotherapy for Hodgkin's disease. Comparative results of MOPP vs ABVD. Eur J Cancer Clin Oncol 1985;21:601-5.

49. Choudhury RC, Jagdale MB, Misra S. Potential transmission of the cytogenetic effects of cisplatin in the male germline cells of Swiss mice. J Chemother 2000;12:352-9.

50. Lampe H, Horwich A, Norman A, Nicholls J, Dearnaley DP. Fertility after chemotherapy for testicular germ cell cancers. J Clin Oncol 1997;15:239-45.

51. Sjöblom T, Parvinen M, Lähdetie J. Stage-specific DNA synthesis of rat spermatogenesis as an indicator of genotoxic effects of vinblastine, mitomycin $\mathrm{C}$ and ionizing radiation on rat spermatogonia and spermatocytes. Mutat Res 1995;331: 181-90.

52. Lu CC, Meistrich ML. Cytotoxic effects of chemotherapeutic drugs on mouse testis cells. Cancer Res 1979;39:3575-82.

53. Bustos-Obregon E, Feito R. The effect of vinblastine sulfate on rat spermatogenesis. Arch Biol (Liege) 1974;85:353-64.

54. Miller BM, Adler ID. Aneuploidy induction in mouse spermatocytes. Mutagenesis 1992;7:69-76.

55. Kallio M, Sjöblom T, Lähdetie J. Effects of vinblastine and colchicine on male rat meiosis in vivo: disturbances in spindle dynamics causing micronuclei and metaphase arrest. Environ Mol Mutagen 1995;25:106-17.

56. van Buul PP, Goudzwaard JH. Bleomycin-induced structural chromosomal aberrations in spermatogonia and bone-marrow cells of mice. Mutat Res 1980;69:319-24.

57. Hsiao W, Stahl PJ, Osterberg EC, Nejat E, Palermo GD, Rosenwaks Z, et al. Successful treatment of postchemotherapy azoospermia with microsurgical testicular sperm extraction: the Weill Cornell experience. J Clin Oncol 2011;29:1607-11.

58. Silber SJ, Nagy Z, Devroey P, Tournaye H, Van Steirteghem AC. Distribution of spermatogenesis in the testicles of azoospermic men: the presence or absence of spermatids in the testes of men with germinal failure. Hum Reprod 1997;12: 2422-8.

59. Schaefer F, Marr J, Seidel C, Tilgen W, Schärer K. Assessment of gonadal maturation by evaluation of spermaturia. Arch Dis Child 1990;65:1205-7.

60. Thomson JA, Itskovitz-Eldor J, Shapiro SS, Waknitz MA, Swiergiel JJ, Marshall VS, et al. Embryonic stem cell lines derived from human blastocysts. Science 1998;282:1145-7.

61. Tilgner K, Atkinson SP, Golebiewska A, Stojkovic M, Lako $\mathrm{M}$, Armstrong L. Isolation of primordial germ cells from differentiating human embryonic stem cells. Stem Cells 2008;26: 3075-85.

62. West FD, Machacek DW, Boyd NL, Pandiyan K, Robbins KR, Stice SL. Enrichment and differentiation of human germ-like cells mediated by feeder cells and basic fibroblast growth factor signaling. Stem Cells 2008;26:2768-76.

63. Aflatoonian B, Ruban L, Jones M, Aflatoonian R, Fazeli A, Moore HD. In vitro post-meiotic germ cell development from human embryonic stem cells. Hum Reprod 2009;24:3150-9. 
64. Takahashi K, Yamanaka S. Induction of pluripotent stem cells from mouse embryonic and adult fibroblast cultures by defined factors. Cell 2006;126:663-76.

65. Yang S, Bo J, Hu H, Guo X, Tian R, Sun C, et al. Derivation of male germ cells from induced pluripotent stem cells in vitro and in reconstituted seminiferous tubules. Cell Prolif 2012;45:
91-100.

66. Brinster RL. Germline stem cell transplantation and transgenesis. Science 2002;296:2174-6.

67. Arnon J, Meirow D, Lewis-Roness H, Ornoy A. Genetic and teratogenic effects of cancer treatments on gametes and embryos. Hum Reprod Update 2001;7:394-403. 